\title{
Glycemic control is not related to cerebral small vessel disease in neurologically asymptomatic individuals with type 1 diabetes
}

\author{
Jussi Inkeri ${ }^{1,2} \cdot$ Krishna Adeshara $^{2,3,4} \cdot$ Valma Harjutsalo $^{2,3,4} \cdot$ Carol Forsblom $^{2,3,4} \cdot$ Ron Liebkind $^{5}$. \\ Turgut Tatlisumak $^{5,6,7}$. Lena M. Thorn ${ }^{2,4,8}$. Per-Henrik Groop ${ }^{2,3,4,9}$. Sara Shams ${ }^{10,11,12}$ • Juha Martola ${ }^{1,11}$. \\ Jukka Putaala ${ }^{5}$. Daniel Gordin ${ }^{3,13,14}$. on behalf of the FinnDiane Study Group
}

Received: 11 August 2021 / Accepted: 22 October 2021 / Published online: 15 November 2021

(c) The Author(s) 2021

\begin{abstract}
Aims To determine if medium- and long-term blood glucose control as well as glycemic variability, which are known to be strong predictors of vascular complications, are associated with underlying cerebral small vessel disease (cSVD) in neurologically asymptomatic individuals with type 1 diabetes.

Methods A total of 189 individuals (47.1\% men; median age 40.0, IQR 33.0-45.2 years) with type 1 diabetes (median diabetes duration of 21.7, IQR 18.3-30.7 years) were enrolled in a cross-sectional retrospective study, as part of the Finnish Diabetic Nephropathy (FinnDiane) Study. Glycated hemoglobin $\left(\mathrm{HbA}_{1 \mathrm{c}}\right)$ values were collected over the course of ten years before the visit including a clinical examination, biochemical sampling, and brain magnetic resonance imaging. Markers of glycemic control, measured during the visit, included $\mathrm{HbA}_{1 \mathrm{c}}$, fructosamine, and glycated albumin.

Results Signs of cSVD were present in 66 (34.9\%) individuals. Medium- and long-term glucose control and glycemic variability did not differ in individuals with signs of cSVD compared to those without. Further, no difference in any of the blood glucose variables and cSVD stratified for cerebral microbleeds $(\mathrm{CMBs})$ or white matter hyperintensities were detected. Neither were numbers of CMBs associated with the studied glucose variables. Additionally, after dividing the studied variables into quartiles, no association with cSVD was observed.

Conclusions We observed no association between glycemic control and cSVD in neurologically asymptomatic individuals with type 1 diabetes. This finding was unexpected considering the large number of signs of cerebrovascular pathology in these people after two decades of chronic hyperglycemia and warrants further studies searching for underlying factors of cSVD.
\end{abstract}

Keywords Cerebral small vessel disease $\cdot$ Magnetic resonance imaging $\cdot$ Fructosamine $\cdot$ Glycated albumin $\cdot$ Long-term glycemic fluctuations

\section{Introduction}

High blood glucose is a major risk factor for not only microvascular complications, but also cardiovascular disease in type 1 diabetes [1,2]. Cardiovascular complications cause significant premature mortality in individuals with type 1 diabetes [3]. Despite the fact that type 1 diabetes increases the risk of stroke fourfold compared to non-diabetic individuals, this grim complication has been less studied than

Managed by Massimo Porta.

Per-Henrik Groop

per-henrik.groop@helsinki.fi

Extended author information available on the last page of the article other cardiovascular consequences [4]. We observed recently that a third of neurologically asymptomatic individuals with type 1 diabetes showed signs of pathological cerebral small vessel disease (cSVD), however, virtually none among the healthy control subjects. Of the different manifestations, white matter hyperintensities (WMHs) were observed in $17 \%$ and cerebral microbleeds (CMBs) in $24 \%$ in our cohort comprised of individuals with type 1 diabetes and a mean age of 40.0 [5]. Our findings resemble those of the Pittsburgh EDC study reporting 33\% of individuals with a mean age of 49.5 years showing signs of white matter hyperintensities (WMHs) in brain magnetic resonance imaging (MRI) [6]. As hemosiderin-sensitive sequences were not part of the MRI protocol in the Pittsburgh cohort CMBs could not be detected. 
Notably, only few of the traditional risk factors were different in type 1 diabetes individuals with and without cSVDs. Blood pressure, a well-known risk factor for cSVD [7], was higher in both individuals with WMHs and CMBs compared to those without [5], and especially nocturnal hypertension was associated cSVD [8]. However, it is unlikely that the modestly higher blood pressure in individuals with cSVD compared to those with no cerebrovascular pathology would fully explain this finding [5]. Neither could we observe a difference in $\mathrm{HbA}_{1 \mathrm{c}}$ at the time of the imaging study. This warrants further analysis of glycemic control in relation to cSVD in this type 1 diabetes cohort with more than two decades of hyperglycemia.

The aim of this study was to retrospectively determine whether medium- or long-term blood glucose control measured by different markers were associated with cSVD in neurologically asymptomatic individuals with type 1 diabetes. Additionally, we sought to investigate whether long-term glycemic fluctuations, known to predict vascular complications in this patient group, are predictive of $\mathrm{cSVD}$.

\section{Methods}

This study was performed as part of the Finnish Diabetic Nephropathy (FinnDiane) Study, a nationwide multicenter study aiming to identify genetic, environmental, and clinical risk factors for micro- and macrovascular complications in type 1 diabetes [5]. A total of 191 individuals with type 1 diabetes were enrolled to the study. Two individuals were excluded due to missing clinical data. Thus, a total of 189 individuals with type 1 diabetes were included in the present study. Age span ranged between 18 and 50 years and the onset of diabetes was $<40$ years. Individuals with renal replacement therapy, any clinical signs of cerebrovascular disease, or contraindications for MRI were excluded from this substudy. The study was carried out in accordance with the Declaration of Helsinki and approved by the Ethics Committee of the Helsinki and Uusimaa Hospital District. Each participant signed a written informed consent [5].

All individuals were studied at the FinnDiane Research Center (Biomedicum) and the Medical Imaging Center at Helsinki University Hospital, both in Helsinki, Finland. Clinical visits included brain MRI scans, biochemical sampling, and a thorough clinical examination. The study visits and methods have been presented in greater detail before [5]. Briefly, brain MRI was performed with a 3.0 T scanner (Achieva; Philips, Best, the Netherlands). The images were assessed by an experienced neuroradiologist (JM) who was blinded to all clinical data. Markers of cSVD were rated per the standardized STRIVE criteria, including the assessment of WMHs (Fazekas scale used, with category $\geq 1$ considered a significant burden), CMBs, and lacunar infarcts [9].

\section{Measures of blood glucose control}

To characterize medium-term glucose control, fructosamine (FA), and glycated albumin (GA), reflecting blood glucose during a time span of two to three weeks, were measured $[10,11]$. Blood glycated hemoglobin $\left(\mathrm{HbA}_{1 \mathrm{c}}\right)$, reflecting blood glucose control during a time span of one to two months, was measured using standardized assays in a central laboratory (Medix Laboratories, Espoo Finland) [12]. Three or more $\mathrm{HbA}_{1 \mathrm{c}}$ values over the course of ten years before the visit (median count 16, IQR 10-23) were obtained in order to calculate overall mean $\mathrm{HbA}_{1 \mathrm{c}}$ $\left(\mathrm{HbA}_{1 \mathrm{c}}-\right.$ mean $\left._{\text {overall }}\right)$ for each individual to better delineate long-term glucose control. These values were collected from local laboratories using standardized methods (HPLC) with a normal range of 4-6\%. Measurements of $\mathrm{HbA}_{1 \mathrm{c}}$ visit-to-visit variability reflects long-term blood glucose fluctuations in a wider timespan of months to years [13]. To assess long-term blood glucose fluctuations $\mathrm{HbA}_{1 \mathrm{c}}$ standard deviation ( $\left.\mathrm{HbA}_{1 \mathrm{c}} \mathrm{SD}\right), \mathrm{HbA}_{1 \mathrm{c}}$ coefficient of variation $\left(\mathrm{HbA}_{1 \mathrm{c}}-\mathrm{CV}\right)$, and $\mathrm{HbA}_{1 \mathrm{c}}$ average real variability $\left(\mathrm{HbA}_{1 \mathrm{c}}-\mathrm{ARV}\right)$ were calculated for each individual. To minimize any effect of a varying number of $\mathrm{HbA}_{1 \mathrm{c}}$ values on long-term glucose variability, adjusted $\mathrm{HbA}_{1 \mathrm{c}}$ standard deviation $\left(\mathrm{HbA}_{1 \mathrm{c}}\right.$-adjSD) were defined for each individual. Of the individuals with type 1 diabetes, 44 had less than three $\mathrm{HbA}_{1 \mathrm{c}}$ values available ten years before the visit, three had missing data on FA or GA and were excluded from the respective analyses.

\section{Determination of glycated albumin (GA)}

GA concentration was determined according to manufacturers' instructions using a competitive ELISA kit (Human glycated albumin ELISA Kit, CSB-E09599h, Cusabio, Wuhan, Hubei Province, China) [14]. Samples were diluted to 1:250 with the sample diluent buffer provided with the kit to achieve sample absorbance within the range of a standard curve. The absorbance was measured at $450 \mathrm{~nm}$ using a Synergy H1 hybrid multi-mode microplate reader (Biotek, Winooski, VT, USA). The amount of GA was determined by comparing with the known standard provided with the kit and expressed as $\mathrm{nM} / \mathrm{ml}$ of GA present in human serum samples.

\section{Determination of fructosamine (FA)}

Serum FA levels were measured by colorimetric technique based on the ability of FA to reduce nitroblue tetrazolium (NBT) to tetrazinolyl radical NBT + , which further 
yields formation of colored formazan under alkaline condition [15]. The developed color intensity was measured at $540 \mathrm{~nm}$ and FA content was calculated using standard 1-deoxy-1 morpholino-D-fructose (0-3.2 mM/L).

\section{Statistics}

Statistical analyses were performed using IBM SPSS Statistics 26.0 (IBM, Armonk, NY). T-tests were used for parametric data and presented as means $( \pm \mathrm{SD})$, and Mann-Whitney- $U$ or Kruskal-Wallis tests for the nonparametric data presented as medians (interquartile range). The $X^{2}$ test or Fisher's exact tests were performed for categorical variables. $\mathrm{HbA}_{1 \mathrm{c}}$-adjSD was calculated according to the formula: $\mathrm{SD} / \sqrt{[\mathrm{n} /(\mathrm{n}-1)]}[16,17] . \mathrm{HbA}_{1 \mathrm{c}}-\mathrm{CV}$ was calculated as the $\mathrm{HbA}_{1 \mathrm{c}}$ (\%) SD divided by the mean and multiplied by 100 , result presented as a percentage and $\mathrm{HbA}_{1 \mathrm{c}}-\mathrm{ARV}$ as the average of the absolute differences between consecutive $\mathrm{HbA}_{1 \mathrm{c}}(\%)$ measurements [18]. The study individuals were divided into three groups based on the number of CMBs (zero, one to two, more than two) and into quartiles based on the $\mathrm{HbA}_{1 \mathrm{c}}, \mathrm{FA}, \mathrm{GA}, \mathrm{HbA}_{1 \mathrm{c}}$-mean overall $_{1 \mathrm{c}}, \mathrm{HbA}_{1 \mathrm{c}}-\mathrm{SD}$, $\mathrm{HbA}_{1 \mathrm{c}}$-adjSD, $\mathrm{HbA}_{1 \mathrm{c}}-\mathrm{CV}$, and $\mathrm{HbA}_{1 \mathrm{c}}-\mathrm{ARV}$ values. Bivariate (Pearson) correlation analysis was used to study correlations between $\mathrm{HbA}_{1 \mathrm{c}}$, FA, GA, and $\mathrm{HbA}_{1 \mathrm{c}}$-mean $_{\text {overall }}$. The threshold for statistical significance was set at $p<0.05$.

\section{Results}

\section{Clinical characteristics}

One hundred and eighty-nine individuals with type 1 diabetes were enrolled for this study, with demographics previously presented in greater detail [5]. Briefly, the median age of the individuals with type 1 diabetes was 40.0 (33.0-45.2) years, $47.1 \%$ were male and median diabetes duration was $21.7(18.3-30.7)$ years. One individual had a history of an acute myocardial infarction, no other cardiovascular events were recorded. Mean systolic blood pressure was $130 \pm 14 \mathrm{mmHg}$. Among cases, 31 (16.9\%) had albuminuria, 20 (10.9\%) microalbuminuria, and 11 (6.0\%) macroalbuminuria. Sixty-six (34.9\%) showed signs of cSVD, 45 (23.8\%) had CMBs, 32 (16.9\%) WMHs, and $4(2.1 \%)$ lacunar infarcts. The overlap between these changes was eleven (5.8\%) for CMBs and WMHs and two $(1.1 \%)$ for both CMBs or WMHs and lacunar infarct. Examples of these MRI findings are presented in Fig. 1. Fifty-five (29.1\%) of the individuals were on insulin pump treatment. Insulin pump treatment did not correlate with the presence of cSVD (data not shown). Median $\mathrm{HbA}_{1 \mathrm{c}}$, GA, and FA values during the visits were $8.1 \%(7.4-8.9 \%),(65.0 \mathrm{mmol} / \mathrm{mol}[57.0-73.0 \mathrm{mmol} /$ $\mathrm{mol}]), 91.6 \mathrm{nM} / \mathrm{ml}(74.3-116.4 \mathrm{nM} / \mathrm{ml})$, and $2.6 \mathrm{mM} / \mathrm{l}$ (2.4-3.0 mM/l), respectively. $\mathrm{HbA}_{1 \mathrm{c}}$-mean $_{\text {overall }}$, collected over the course of ten years before the visit (median count 16 , IQR 10-23), were $8.1 \pm 0.9 \%(65.4 \pm 10.3 \mathrm{mmol} /$ mol) (Table 1). Bivariate correlations between $\mathrm{HbA}_{1 \mathrm{c}}$, FA, GA, and $\mathrm{HbA}_{1 \mathrm{c}}-$ mean $_{\text {overall }}$ are presented in Supplementary Table 1 . An association was observed between
Fig. 1 MRI findings of cerebral small vessel disease. Fluid attenuated inversion recovery image (FLAIR) with white matter hyperintensity (arrow) (a). Susceptibility weighted image (SWI) with cerebral microbleeds (arrows) (b)

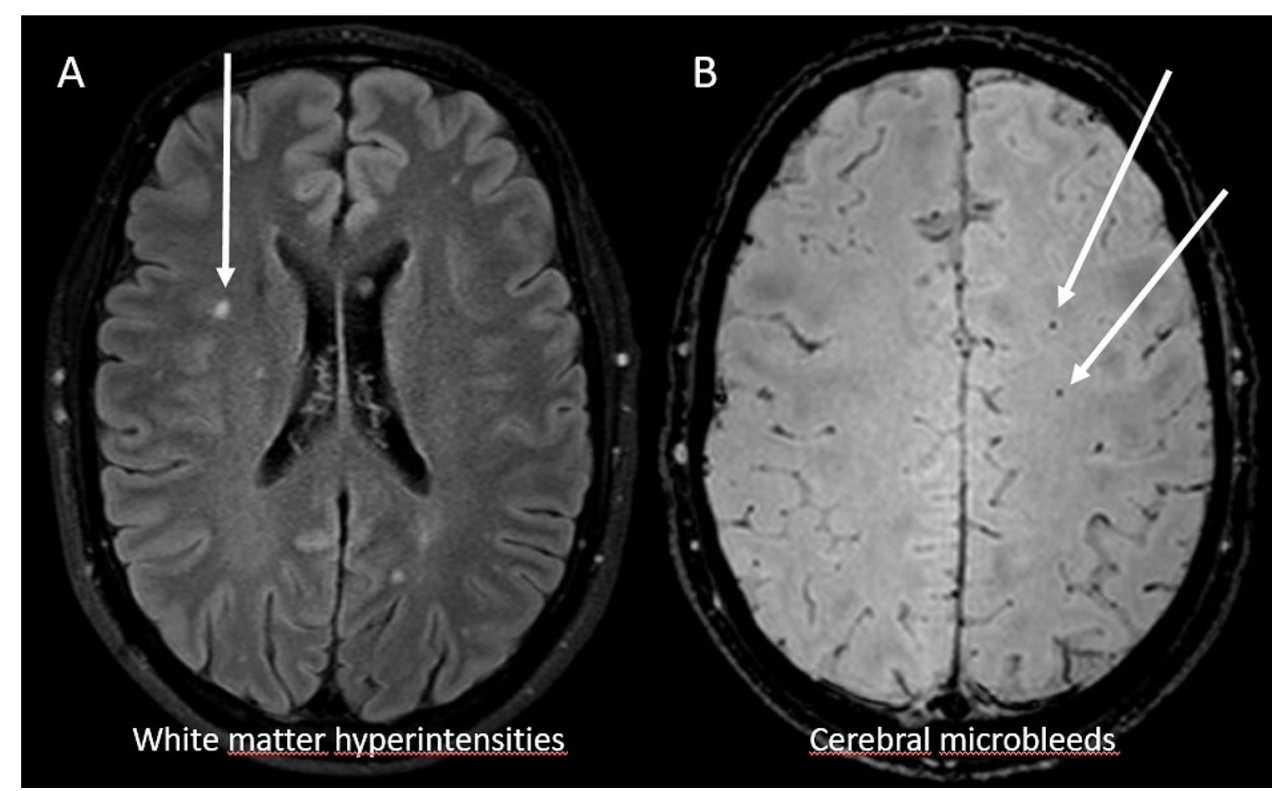


Table 1 Clinical characteristics of the study population

\begin{tabular}{|c|c|}
\hline & $\begin{array}{l}\text { Individuals with } \\
\text { type } 1 \text { diabetes } \\
n=189\end{array}$ \\
\hline Age, years & $40.0(33.0-45.2)$ \\
\hline Male sex & $89(47.1)$ \\
\hline Diabetes duration, years & $21.7(18.3-30.7)$ \\
\hline Cerebral small vessel disease & $66(34.9)$ \\
\hline Cerebral microbleeds & $45(23.8)$ \\
\hline White matter hyperintensities & $32(16.9)$ \\
\hline Lacunae & $4(2.1)$ \\
\hline Systolic blood pressure, $\mathrm{mmHg}$ & $130 \pm 14$ \\
\hline Total cholesterol, mmol/L, median & $4.4(4.0-4.9)$ \\
\hline High-density lipoprotein, mmol/L, median & $1.4(1.2-1.7)$ \\
\hline Low-density lipoprotein, mmol/L, median & $2.4(2.1-3.0)$ \\
\hline Triglycerides, $\mathrm{mmol} / \mathrm{L}$, median & $0.9(0.7-1.4)$ \\
\hline Albuminuria & $31(16.9)$ \\
\hline Microalbuminuria & $20(10.9)$ \\
\hline Macroalbuminuria & $11(6.0)$ \\
\hline $\begin{array}{l}\text { Estimated glomerular filtration rate, } \mathrm{ml} / \mathrm{min} / 1.73 \\
\mathrm{~m}^{2}\end{array}$ & $108.2(96.4-115.8)$ \\
\hline $\mathrm{HbA}_{1 \mathrm{c}}, \%$ & $8.1(7.4-8.9)$ \\
\hline $\mathrm{HbA}_{1 \mathrm{c}}, \mathrm{mmol} / \mathrm{mol}$ & $65.0(57.0-73.0)$ \\
\hline Glycated albumin, $\mathrm{nM} / \mathrm{ml}$ & $91.6(74.3-116.4)$ \\
\hline Fructosamine, $\mathrm{mM} / \mathrm{l}$ & $2.6(2.4-3.0)$ \\
\hline $\mathrm{HbA}_{1 \mathrm{c}}$ count, $\mathrm{n}$ & $16(10-23)$ \\
\hline $\mathrm{HbA}_{1 \mathrm{c}}-$ mean $_{\text {overall, }} \%$ & $8.1 \pm 0.9$ \\
\hline $\mathrm{HbA}_{1 \mathrm{c}}-\mathrm{mean}_{\text {overall, }}, \mathrm{mmol} / \mathrm{mol}$ & $65.4 \pm 10.3$ \\
\hline $\mathrm{HbA}_{1 \mathrm{c}}$ standard deviation, $\%$ & $0.59(0.44-0.81)$ \\
\hline $\mathrm{HbA}_{1 \mathrm{c}}$ adjusted standard deviation, $\%$ & $0.56(0.43-0.76)$ \\
\hline $\mathrm{HbA}_{1 \mathrm{c}}$ coefficient of variation, $\%$ & $7.2(5.6-9.6)$ \\
\hline $\mathrm{HbA}_{1 \mathrm{c}}$ average real variability & $0.5(0.4-0.6)$ \\
\hline
\end{tabular}

Data are $n(\%)$, median (interquartile range) or mean \pm SD unless otherwise indicated

$\mathrm{HbA}_{1 \mathrm{c}}$ vs. FA $(p=0.018)$ and $\mathrm{HbA}_{1 \mathrm{c}}$ vs. $\mathrm{HbA}_{1 \mathrm{c}}$-mean ${ }_{\text {overall }}$ $(p<0.001)$. To overcome the possibility of bias by the number of $\mathrm{HbA}_{1 \mathrm{c}}$ measurements we divided the study individuals into two groups, above and below median $\mathrm{HbA}_{1 \mathrm{c}}$ count. The presence of cSVD were not different between the groups (24 [30.8\%] vs. 29 [43.3\%], $p=0.119)$.

Individuals with CMBs or WMHs had higher systolic blood pressure compared to those without CMBs or WMHs $(135 \pm 17 \mathrm{mmHg}$ vs. $129 \pm 13 \mathrm{mmHg}, p=0.011$ for CMBs and $137 \pm 15 \mathrm{mmHg}$ vs. $129 \pm 14 \mathrm{mmHg}$, $p=0.005$ for WMHs). The presence of WMHs correlated also with age (45.0 [40.4-47.6] years vs. 38.6 [32.5-44.2] years, $p<0.001)$ and the presence of CMBs with albuminuria (13 [30.2\%] vs. 18 [12.9\%], $p=0.008)$. The other demographic variables were not associated with CMBs or WMHs.

\section{Medium- and long-term blood glucose control and CSVD}

$\mathrm{HbA}_{1 \mathrm{c}}$ at the study visit did not correlate with the presence of cSVD $(8.2 \%$ [7.6-8.9\%], $66.0 \mathrm{mmol} / \mathrm{mol}$ [59.8-73.3 mmol/ $\mathrm{mol}]$ vs. $8.0 \%$ [7.3-8.8\%], $64.0 \mathrm{mmol} / \mathrm{mol}[56.0-73.0 \mathrm{mmol} /$ mol], $p=0.259)$, CMBs, or WMHs in individuals with type 1 diabetes. GA and FA did not correlate with cSVD (97.2 [73.9-117.8] nM/ml vs. 89.6 [76.3-115.9] nM/ml, $p=0.704$ for $\mathrm{GA}$ and $2.6[2.4-2.9] \mathrm{mM} / 1$ vs. $2.5[2.3-3.0]$ $\mathrm{mM} / 1 p=0.587$ for FA), CMBs, or WMHs in brain MRIs (Table 2). Furthermore, individuals with type 1 diabetes divided into quartiles based on their $\mathrm{HbA}_{1 \mathrm{c}}, \mathrm{GA}$, and FA values showed no correlations with the presence on CSVD markers (Table 3). Neither did we observe associations between $\mathrm{HbA}_{1 \mathrm{c}}$, GA, and FA and the number of CMBs (Table 4).

Differences in $\mathrm{HbA}_{1 \mathrm{c}}$-mean ${ }_{\text {overall }}$ value, collected within ten years prior to the study visit, were not observed between those type 1 diabetes individuals with any signs of cSVD in their brain MRIs compared to those without $(8.3 \pm 1.0 \%$ $[67.4 \pm 11.2 \mathrm{mmol} / \mathrm{mol}]$ vs. $8.0 \pm 0.9 \%[64.2 \pm 9.5 \mathrm{mmol} /$ mol], $p=0.141$ ) (Table 2). This was also true when analyzing separately the cerebral changes CMBs and WMHs. We observed no associations between cumulative blood glucose values and cSVDs or the number of CMBs after dividing individuals with type 1 diabetes into quartiles based on the $\mathrm{HbA}_{1 \mathrm{c}}$-mean $_{\text {overall }}$ (Tables 3 and 4).

\section{Glycemic variability and cSVD}

Long-term $\mathrm{HbA}_{1 \mathrm{c}}$ variability, measured as $\mathrm{HbA}_{1 \mathrm{c}}-\mathrm{SD}$ (0.57\% [0.42-0.78\%] vs. 0.61\% [0.44-0.81\%], $p=0.655$, $\mathrm{HbA}_{1 \mathrm{c}}$-adjSD (0.55\% [0.40-0.73\%] vs. 0.58\% [0.43-0.78\%], $p=0.771, \mathrm{HbA}_{1 \mathrm{c}}-\mathrm{CV}(6.7 \%$ [5.5-8.7\%] vs. 7.6\% [5.7-9.9\%], $p=0.245)$, and $\mathrm{HbA}_{1 \mathrm{c}}-\mathrm{ARV}(0.5$ [0.4-0.6] vs. 0.5 [0.3-0.7], $p=0.953$ ), did not correlate with the presence of cSVD. Similarly, no correlation was observed between glycemic variability and WMHs, CMBs, or the number of CMBs (Tables 2 and 4). After dividing the population into quartiles of $\mathrm{HbA}_{1 \mathrm{c}}$ variability, no correlation was observed with the presence of cSVD, CMBs or WMHs observed in brain MRI (Table 3).

\section{Discussion}

The main finding of our study was that medium- and longterm blood glucose control and glycemic variability showed no association with cSVD in neurologically asymptomatic individuals with type 1 diabetes after two decades of chronic 
Table $2 \mathrm{HbA}_{1 \mathrm{c}}$, glycated albumin, fructosamine, and long-term glycemic variability stratified by small vessel disease findings in brain MRI in individuals with type 1 diabetes

\begin{tabular}{|c|c|c|c|c|c|c|c|c|c|}
\hline & \multicolumn{3}{|c|}{ Cerebral small vessel disease } & \multicolumn{3}{|c|}{ Cerebral microbleeds } & \multicolumn{3}{|c|}{ White matter hyperintensities } \\
\hline & $\begin{array}{l}\text { Presence } \\
(n=66)\end{array}$ & $\begin{array}{l}\text { Absence } \\
(n=123)\end{array}$ & $p$ & $\begin{array}{l}\text { Presence } \\
(n=45)\end{array}$ & $\begin{array}{l}\text { Absence } \\
(n=144)\end{array}$ & $p$ & $\begin{array}{l}\text { Presence } \\
(n=32)\end{array}$ & $\begin{array}{l}\text { Absence } \\
(n=157)\end{array}$ & $p$ \\
\hline $\begin{array}{l}\mathrm{HbA}_{1 \mathrm{c}}, \%, \\
\quad(\mathrm{mmol} / \mathrm{mol})\end{array}$ & $\begin{array}{l}8.2(7.6-8.9), \\
\quad(66.0 \\
[59.8-73.3])\end{array}$ & $\begin{array}{l}8.0(7.3-8.8), \\
\quad(64.0 \\
\quad[56.0-73.0])\end{array}$ & 0.259 & $\begin{array}{l}8.2(7.6-8.9) \\
\quad(66.0 \\
\quad[60.0-73.0])\end{array}$ & $\begin{array}{l}8.1(7.4-8.8), \\
\quad(65.0 \\
\quad[57.0-73.0])\end{array}$ & 0.419 & $\begin{array}{l}8.2(7.4-8.7), \\
\quad(65.5 \\
[58.3-72.0])\end{array}$ & $\begin{array}{l}8.1(7.4-8.9), \\
\quad(65.0 \\
\quad[57.0-73.0])\end{array}$ & 0.838 \\
\hline $\mathrm{GA}, \mathrm{nM} / \mathrm{ml}$ & $\begin{array}{c}97.2(73.9- \\
117.8)\end{array}$ & $\begin{array}{c}89.6(76.3- \\
115.9)\end{array}$ & 0.704 & $\begin{array}{c}102.9(73.9- \\
125.3)\end{array}$ & $\begin{array}{c}90.3(76.3- \\
115.2)\end{array}$ & 0.580 & $\begin{array}{l}98.0(82.6- \\
113.7)\end{array}$ & $\begin{array}{c}89.8(74.0- \\
117.8)\end{array}$ & 0.492 \\
\hline $\mathrm{FA}, \mathrm{mM} / 1$ & $2.6(2.4-2.9)$ & $2.5(2.3-3.0)$ & 0.587 & $2.6(2.4-2.9)$ & $2.5(2.3-3.0)$ & 0.439 & $2.6(2.4-3.0)$ & $2.6(2.4-3.0)$ & 0.429 \\
\hline $\begin{array}{l}\mathrm{HbA}_{1 \mathrm{c}}-\mathrm{mean}- \\
\quad \text { overall }, \% \\
\quad(\mathrm{mmol} / \mathrm{mol})\end{array}$ & $\begin{array}{l}8.3 \pm 1.0 \\
\quad(67.4 \pm 11.2)\end{array}$ & $\begin{array}{l}8.0 \pm 0.9 \\
\quad(64.2 \pm 9.5)\end{array}$ & 0.141 & $\begin{array}{l}8.3 \pm 0.9 \\
\quad(67.2 \pm 10.3)\end{array}$ & $\begin{array}{l}8.1 \pm 0.9 \\
\quad(64.7 \pm 10.2)\end{array}$ & 0.280 & $\begin{array}{l}8.2 \pm 1.1 \\
\quad(66.4 \pm 12.0)\end{array}$ & $\begin{array}{l}8.1 \pm 0.9 \\
\quad(65.1 \pm 9.9)\end{array}$ & 0.787 \\
\hline $\mathrm{HbA}_{1 \mathrm{c}}-\mathrm{SD}, \%$ & $\begin{array}{l}0.57(0.42- \\
0.78)\end{array}$ & $\begin{array}{l}0.61(0.44- \\
0.81)\end{array}$ & 0.655 & $\begin{array}{l}0.56(0.42- \\
0.76)\end{array}$ & $\begin{array}{l}0.61(0.44- \\
0.82)\end{array}$ & 0.514 & $\begin{array}{l}0.52(0.39- \\
0.97)\end{array}$ & $\begin{array}{l}0.61(0.46- \\
0.81)\end{array}$ & 0.445 \\
\hline $\begin{array}{l}\mathrm{HbA}_{1 \mathrm{c}} \text {-adjSD } \\
\%\end{array}$ & $\begin{array}{l}0.55(0.40- \\
0.73)\end{array}$ & $\begin{array}{l}0.58(0.43- \\
0.78)\end{array}$ & 0.771 & $\begin{array}{l}0.53(0.40- \\
0.72)\end{array}$ & $\begin{array}{l}0.58(0.43- \\
0.79)\end{array}$ & 0.577 & $\begin{array}{l}0.51(0.39- \\
0.93)\end{array}$ & $\begin{array}{l}0.57(0.44- \\
0.75)\end{array}$ & 0.480 \\
\hline $\mathrm{HbA}_{1 \mathrm{c}}-\mathrm{CV}, \%$ & $6.7(5.5-8.7)$ & $7.6(5.7-9.9)$ & 0.245 & $6.7(5.5-8.5)$ & $7.4(5.7-10.1)$ & 0.219 & $6.0(5.0-11.5)$ & $7.5(5.8-9.5)$ & 0.293 \\
\hline $\mathrm{HbA}_{1 \mathrm{c}}-\mathrm{ARV}$ & $0.5(0.4-0.6)$ & $0.5(0.3-0.7)$ & 0.953 & $0.5(0.4-0.6)$ & $0.5(0.4-0.6)$ & 0.578 & $0.4(0.4-0.6)$ & $0.5(0.4-0.7)$ & 0.410 \\
\hline
\end{tabular}

Data are median (interquartile range) or mean \pm SD unless otherwise indicated. $G A=$ glycated albumin, $F A=$ fructosamine, $\mathrm{SD}=$ standard deviation, adjSD = adjusted standard deviation, $\mathrm{CV}=$ coefficient of variation, $\mathrm{ARV}=$ average real variability

Table $3 \mathrm{HbA}_{1 \mathrm{c}}$, glycated albumin, fructosamine, and long-term glycemic variability lowest and highest quartile crosstabs by small vessel disease findings in brain MRI in individuals with type 1 diabetes

\begin{tabular}{|c|c|c|c|c|c|c|c|c|c|}
\hline & \multicolumn{3}{|c|}{ Cerebral small vessel disease } & \multicolumn{3}{|c|}{ Cerebral microbleeds } & \multicolumn{3}{|c|}{ White matter hyperintensities } \\
\hline & Presence & Absence & $p$ & Presence & Absence & $p$ & Presence & Absence & $p$ \\
\hline $\mathrm{HbA}_{1 \mathrm{c}}$, highest quartile & $18(54.4)$ & $29(56.7)$ & 0.289 & $12(57.1)$ & $35(44.3)$ & 0.295 & $7(46.7)$ & $40(47.1)$ & 0.978 \\
\hline $\mathrm{HbA}_{1 \mathrm{c}}$, lowest quartile & $15(45.5)$ & $38(56.7)$ & & $9(42.9)$ & $44(55.7)$ & & $8(53.3)$ & $45(52.9)$ & \\
\hline GA, highest quartile & $17(50)$ & $29(50)$ & 1.000 & $14(53.8)$ & $32(48.5)$ & 0.643 & $6(54.5)$ & $40(49.4)$ & 0.748 \\
\hline GA, lowest quartile & $17(50)$ & $29(50)$ & & $12(46.2)$ & $34(51.5)$ & & $5(45.5)$ & $41(50.6)$ & \\
\hline FA, highest quartile & $14(53.8)$ & $33(50.8)$ & 0.791 & $10(58.8)$ & $37(50)$ & 0.512 & $10(62.5)$ & $37(49.3)$ & 0.339 \\
\hline FA, lowest quartile & $12(46.2)$ & $32(49.2)$ & & $7(41.2)$ & $37(50)$ & & $6(37.5)$ & $38(50.7)$ & \\
\hline $\mathrm{HbA}_{1 \mathrm{c}}-\mathrm{mean}_{\text {overall }}$, highest quartile & $16(57.1)$ & $20(45.5)$ & 0.334 & $11(57.9)$ & $25(47.2)$ & 0.422 & $7(50)$ & $29(50)$ & 1.000 \\
\hline $\mathrm{HbA}_{1 \mathrm{c}}-\mathrm{mean}_{\text {overall }}$, lowest quartile & $12(42.9)$ & $24(54.5)$ & & $8(42.1)$ & $28(52.8)$ & & $7(50)$ & $29(50)$ & \\
\hline $\mathrm{HbA}_{1 \mathrm{c}}-\mathrm{SD}$, highest quartile & $12(48.0)$ & $24(52.2)$ & 0.737 & $7(43.8)$ & $29(52.7)$ & 0.527 & $7(46.7)$ & $29(51.8)$ & 0.725 \\
\hline $\mathrm{HbA}_{1 \mathrm{c}}-\mathrm{SD}$, lowest quartile & $13(52.0)$ & $22(47.8)$ & & $9(56.3)$ & $26(47.3)$ & & $8(53.3)$ & $27(48.2)$ & \\
\hline $\mathrm{HbA}_{1 \mathrm{c}}$-adjSD, highest quartile & $12(44.4)$ & $24(51.1)$ & 0.583 & 7 (38.9) & $29(51.8)$ & 0.341 & $7(41.2)$ & $29(50.9)$ & 0.482 \\
\hline $\mathrm{HbA}_{1 \mathrm{c}}$-adjSD, lowest quartile & $15(55.6)$ & $23(48.9)$ & & $11(61.1)$ & $27(48.2)$ & & $10(58.8)$ & $28(49.1)$ & \\
\hline $\mathrm{HbA}_{1 \mathrm{c}}-\mathrm{CV}$, highest quartile & $12(44.4)$ & $24(53.3)$ & 0.465 & $7(41.2)$ & $29(52.7)$ & 0.405 & $7(41.2)$ & $29(52.7)$ & 0.405 \\
\hline $\mathrm{HbA}_{1 \mathrm{c}}-\mathrm{CV}$, lowest quartile & $15(55.6)$ & $21(46.7)$ & & $10(58.8)$ & $26(47.3)$ & & $10(58.8)$ & $26(47.3)$ & \\
\hline $\mathrm{HbA}_{1 \mathrm{c}}-\mathrm{ARV}$, highest quartile & $11(54.2)$ & $25(48.1)$ & 0.739 & $9(56.3)$ & $27(47.4)$ & 0.530 & $4(44.4)$ & $32(50)$ & 0.518 \\
\hline $\mathrm{HbA}_{1 \mathrm{c}}-\mathrm{ARV}$, lowest quartile & $10(47.6)$ & $27(51.9)$ & & $7(43.8)$ & $30(52.6)$ & & $5(55.6)$ & $32(50)$ & \\
\hline
\end{tabular}

Data are $\mathrm{n}(\%) . \mathrm{GA}=$ glycated albumin, $\mathrm{FA}=$ fructosamine, $\mathrm{SD}=$ standard deviation, adjSD $=$ adjusted standard deviation, $\mathrm{CV}=$ coefficient of variation, ARV = average real variability

hyperglycemia. Our study results suggest that factors other than blood glucose control are central in the development of cSVD in type 1 diabetes.

Risk factors for cSVD, especially for CMBs, are scarcely studied in type 1 diabetes. The Pittsburgh EDC study reported no association between WMHs and chronic hyperglycemia measured as $\mathrm{HbA}_{1 \mathrm{c}}$ [6]. Similar findings were reported in another cohort consisting of 114 individuals with type 1 diabetes [19]. Our findings are in concordance with these previous studies, further extending their observations 
Table $4 \mathrm{HbA}_{1 \mathrm{c}}$, glycated albumin, fructosamine and long-term glycemic variability by number of cerebral microbleeds in individuals with type 1 diabetes

\begin{tabular}{|c|c|c|c|c|}
\hline & \multicolumn{4}{|l|}{ Number of cerebral microbleeds } \\
\hline & $0(n=144)$ & $1-2(n=33)$ & 3 or more $(n=12)$ & $p$ \\
\hline $\mathrm{HbA}_{1 \mathrm{c}}, \%,(\mathrm{mmol} / \mathrm{mol})$ & $8.1(7.4-8.8),(65.0[57.0-73.0])$ & $8.2(7.6-8.8),(66.0[59.5-72.0])$ & $8.3(7.7-9.4),(66.5[61.3-79.0])$ & 0.470 \\
\hline $\mathrm{GA}, \mathrm{mM} / \mathrm{l}$ & $90.3(76.3-115.2)$ & $98.4(72.4-121.9)$ & $106.9(81.8-133.0)$ & 0.677 \\
\hline $\mathrm{FA}, \mathrm{mM} / \mathrm{l}$ & $2.5(2.3-3.0)$ & $2.5(2.4-2.9)$ & $2.8(2.8-3.1)$ & 0.066 \\
\hline $\mathrm{HbA}_{1 \mathrm{c}}-\mathrm{mean}_{\text {overall }}, \%,(\mathrm{mmol} / \mathrm{mol})$ & $8.1 \pm 0.9,(64.7 \pm 10.2)$ & $8.2 \pm 0.8,(66.2 \pm 8.8)$ & $8.6 \pm 1.2,(70.1 \pm 13.6)$ & 0.403 \\
\hline $\mathrm{HbA}_{1 \mathrm{c}}-\mathrm{SD}, \%$ & $0.61(0.44-0.82)$ & $0.57(0.39-0.83)$ & $0.55(0.48-0.68)$ & 0.702 \\
\hline $\mathrm{HbA}_{1 \mathrm{c}}$-adjSD, \% & $0.58(0.42-0.79)$ & $0.56(0.36-0.76)$ & $0.52(0.45-0.66)$ & 0.735 \\
\hline $\mathrm{HbA}_{1 \mathrm{c}}-\mathrm{CV}, \%$ & $7.4(5.7-10.1)$ & $6.8(5.4-9.8)$ & $6.6(5.5-7.9)$ & 0.334 \\
\hline $\mathrm{HbA}_{1 \mathrm{c}}-\mathrm{ARV}$ & $0.5(0.4-0.6)$ & $0.5(0.4-0.6)$ & $0.6(0.4-0.7)$ & 0.718 \\
\hline
\end{tabular}

Data are median (interquartile range) or mean $\pm \mathrm{SD}$ unless otherwise indicated. $\mathrm{GA}=$ glycated albumin, $\mathrm{FA}=$ fructosamine, $\mathrm{SD}=$ standard deviation, adjSD = adjusted standard deviation, $\mathrm{CV}=$ coefficient of variation, $\mathrm{ARV}=$ average real variability

by carefully characterizing blood glucose control as well as deepening the cerebrovascular phenotype. We measured cumulative blood glucose and glycemic variability after collecting $\mathrm{HbA}_{1 \mathrm{c}}$ values over a course of ten years before the study visit. Furthermore, medium-term glucose control was estimated by adding two established glycemic markers, namely FA and GA, into the analyses. Lastly, in contrast to prior studies, CMBs being strongly associated with future strokes and mortality $[20,21]$ were identified from brain MRI scans in our study in contrast to only WMHs and lacunes in previous studies.

A third of the individuals in our population of neurologically asymptomatic individuals with type 1 diabetes showed signs of pathological cSVD. However, hardly any cerebrovascular changes were observed in the normoglycemic healthy control subjects. Only a few established clinical risk factors were different in individuals with and without cSVDs. Notably, differences in these risk factors, namely blood pressure and albuminuria, were only modestly explaining the cerebral findings [5]. It is, thus, surprising that variables reflecting blood glucose control at the time of the brain MRI study, cumulative blood glucose levels prior to the study, or blood glucose variability showed no associations with vascular pathology detected in brain MRI.

Individuals with type 1 diabetes have a markedly increased risk for cardiovascular morbidity and mortality compared to the healthy population [22]. We have previously shown that $\mathrm{HbA}_{1 \mathrm{c}}$ is an independent risk factor for ischemic but not for hemorrhagic stroke [23]. Similarly, intensive diabetes therapy reduced a pooled cardiovascular disease (CVD) end-point consisting of nonfatal myocardial infarction, stroke and death by 57 percent in the Diabetes Control and Complications Trial (DCCT) and the Epidemiology of Diabetes Interventions and Complications (EDIC) Study [2]. It may well be that CVD outcomes in these longitudinal studies were partly secondary to diabetic kidney disease
(DKD), a strong risk factor for cerebrovascular disease, whereas $83.1 \%$ of the participants in our study, showed no signs of DKD. This raises the question whether the detrimental effect of hyperglycemia on the cerebrovascular bed is mediated via diabetic microvascular complications, and kidney disease in particular.

Glycemic variability has been suggested to cause cellular damage in different organs, particularly via oxidative stress [24]. We have shown long-term glucose variability, measured as $\mathrm{SD}$ of longitudinal $\mathrm{HbA}_{1 \mathrm{c}}$ values, to predict incident of microalbuminuria, progression of renal disease, and cardiovascular disease events in type 1 diabetes [13]. Similar findings were reported in another study, where $\mathrm{HbA}_{1 \mathrm{c}}$ variability predicted retinopathy, nephropathy, and cardiac autonomic neuropathy in adolescents with type 1 diabetes [25]. The DCCT Study reported $\mathrm{HbA}_{1 \mathrm{c}}$ variability to contribute to the development of retinopathy and nephropathy, whereas short-term glucose variability did not predict the development of these complications [16, 26, 27]. Previous reports showed no strong association of FA with severity of hemiparesis and predicted stroke outcome in general population with brain infarction of the carotid territory [28] and in individuals with cerebral hemorrhage at an early stage of their illness [29]. Also, GA has shown different impact on stroke outcomes being associated with only large artery atherosclerosis but not with small vessel occlusion and cardioembolism in diabetic individuals with acute ischemic stroke [30]. However, other study reported association of GA with early neurological deterioration in prediabetic individuals with acute ischemic stroke [31]. Reflecting short-term glycemia, FA and GA levels can be affected by acute blood glucose change, albumin turnover or metabolism [32] and therefore reflects its variability in a disease specific manner. These observations and present findings suggest that an abnormal level of glycemic biomarkers reflect metabolic illness but does not exacerbate an acute manifestation of 
cerebrovascular changes. Future studies are needed to investigate whether short-term glucose control and variability contribute to the risk of cSVD, especially CMBs in type 1 diabetes.

High blood glucose is the main driver of diabetic retinopathy, another form of cerebrovascular disease, in type 1 diabetes [33]. It is thus of interest that the number of CMBs has earlier been shown to be higher in individuals with type 1 diabetes and severe diabetic retinopathy [34]. Similarly, the prevalence of WMHs and/or lacunes has been shown to correlate with diabetic retinopathy in type 2 diabetes [35]. We did also observe an association between CMBs and diabetic retinal disease [36]. This association was, however, independent of $\mathrm{HbA}_{1 \mathrm{c}}$ reflecting the strong relationship between blood glucose and diabetic retinal disease. The findings that the blood glucose levels were associated with diabetic retinopathy albeit not cSVD raises the question, whether the mechanisms of the adverse effects of hyperglycemia on the central nervous system could be different from those in the retina. It may well be that changes in multiple metabolic factors induced by diabetes contribute differently to the abnormalities in the cerebral and the retinal vasculature. Further studies on potential metabolic changes in our cohort are now ongoing to address this question.

It is of note that the glucose levels on both sides of the blood brain barrier, namely blood and cerebrospinal fluid, may not be identical. Important regulators are involved in this delicate balance such as glucose transporters (GLUTs) to maintain the continuous high glucose and energy demands of the brain [37, 38]. Mechanistic studies are warranted to give an answer whether GLUTs could explain these findings. Interestingly, poorly controlled diabetes mellitus can cause a variety of adverse effects on brain function and metabolism via both low and high blood glucose levels [37]. These blood glucose alterations in diabetes mellitus can affect cerebral neurotransmitter metabolism, cerebral blood flow, and blood-brain barrier [37, 39]. Particularly dysfunction of the blood-brain barrier has been suggested to relate to intracerebral hemorrhage and the presence of CMBs [40]. Whether a damaged blood-brain barrier explains the number of CMBs in our cohort is not known. Neither if such changes could be caused by a poor glycemic control.

Our study does not go without limitations. We had serial A1c values from ten years enabling us to assess both cumulative blood glucose control and blood glucose variability. The cross-sectional retrospective nature of the study should, however, be taken into account. Our study had no data regarding short-term glucose control such as time in range (TIR) or variability measured from continuous glucose monitoring systems (CGMS), leaving this interesting topic open for future studies. The number of participants and $\mathrm{HbA}_{1 \mathrm{c}}$ measurements, reflecting long-term blood glucose levels and fluctuations, is limited and this may have an effect on the statistical power to detect differences between the groups. A larger cohort would have enabled greater statistical power. It is, however, improbable that this would markedly have changed the results considering the consistence of the observations. The strengths of this study are the standardized imaging and clinical assessment, as well as the strong phenotypic data.

\section{Conclusion}

We observed no association between medium- and longterm blood glucose control and long-term glycemic variability and cSVD in neurologically asymptomatic individuals with type 1 diabetes. This finding was unexpected considering the large number of signs of cerebrovascular pathology in these people after two decades of chronic hyperglycemia and warrants further studies searching for underlying factors of cSVD.

Supplementary Information The online version contains supplementary material available at https://doi.org/10.1007/s00592-021-01821-8.

Acknowledgements The authors deeply acknowledge the technical assistance of Anna Sandelin, Jaana Tuomikangas, and Mira Korolainen. They also thank Pentti Pölönen, HUS Medical Imaging Center, Helsinki University Hospital, for performing the MRI scans.

Author contributions JI, KA, VH, CF, RL, TT, LMT, P-HG, SS, JM, JP, and DG contributed to the study design and acquisition of data, as well as the interpretation of data. JI, KA, VH, JM, JP, and DG had the main responsibility for analyzing data and writing the first draft of the paper. JI, KA, VH, CF, RL, TT, LMT, P-HG, SS, JM, JP, and DG critically revised the manuscript. P-HG is the guarantor of this work and, as such, had full access to all the data in the study and takes responsibility for the integrity of the data and the accuracy of the data analysis.

Funding Open Access funding provided by University of Helsinki including Helsinki University Central Hospital. The FinnDiane study was supported by grants from Folkhälsan Research Foundation, Academy of Finland (316664), Wilhelm and Else Stockmann Foundation, Liv och Hälsa Society, Novo Nordisk Foundation (NNF OC0013657), Sigrid Juselius Foundation, Päivikki and Sakari Sohlberg Foundation, Finnish Foundation for Cardiovascular Research, and by governmental research funding. D.G. was supported by Wilhelm and Else Stockmann Foundation, Liv och Hälsa Society, Medical Society of Finland (Finska Läkaresällskapet), Dorothea Olivia, Karl Walter and Jarl Walter Perklén's Foundation, Päivikki and Sakari Sohlberg Foundation, Sigrid Juselius Foundation, the University of Helsinki (Clinical Researcher stint), and the Academy of Finland (UAK1021MRI). T.T. has received research funding from University of Gothenburg, Sahlgrenska University Hospital, European Union, Sigrid Juselius Foundation, and Wennerström Foundation. None of the funding bodies had any role in the study design; collection, analysis, or interpretation of data; writing of the manuscript; or the decision to submit the manuscript for publication. 
Availability of data and materials The database is available for all FinnDiane researchers.

\section{Declarations}

Conflict of interest D.G. Lecture or advisory honoraria: AstraZeneca, Boehringer Ingelheim, Delta Medical Communications, Fresenius, GE Healthcare, Kidney and Liver Foundation in Finland, Novo Nordisk. Support to attend medical meetings: CVRx., Sanofi Aventis. J.M. Lecture Honoria Santen. T.T. has/has had research contracts with Bayer, Boehringer Ingelheim, and Portola Pharm. He has been advisory board member for Bayer, Boehringer Ingelheim, Bristol Myers Squibb, and Portola Pharm. P.-H.G. has received lecture honoraria from AstraZeneca, Boehringer Ingelheim, Eli Lilly, Elo Water, Genzyme, Medscape, Merck Sharp \& Dohme (MSD), Mundipharma, Novartis, Novo Nordisk, PeerVoice, Sanofi, SCIARC, and is an advisory board member of AbbVie, Bayer, Boehringer Ingelheim, Eli Lilly, Janssen, Medscape, MSD, Novartis, Novo Nordisk, and Sanofi. No other potential conflicts of interest relevant to this article were reported.

Ethical approval The study was carried out in accordance with the Declaration of Helsinki and approved by the Ethics Committee of the Helsinki and Uusimaa Hospital District.

Consent to participate Each participant signed a written informed consent before participation.

Open Access This article is licensed under a Creative Commons Attribution 4.0 International License, which permits use, sharing, adaptation, distribution and reproduction in any medium or format, as long as you give appropriate credit to the original author(s) and the source, provide a link to the Creative Commons licence, and indicate if changes were made. The images or other third party material in this article are included in the article's Creative Commons licence, unless indicated otherwise in a credit line to the material. If material is not included in the article's Creative Commons licence and your intended use is not permitted by statutory regulation or exceeds the permitted use, you will need to obtain permission directly from the copyright holder. To view a copy of this licence, visit http://creativecommons.org/licenses/by/4.0/.

\section{References}

1. The Diabetes Control and Complications Trial Research Group (1993) The effect of intensive treatment of diabetes on the development and progression of long-term complications in insulindependent diabetes mellitus. N Engl J Med 329 (14):977-986

2. The Diabetes Control and Complications Trial/Epidemiology of Diabetes Interventions and Complications (DCCT/EDIC) Study Research Group (2005) Intensive diabetes treatment and cardiovascular disease in patients with type 1 diabetes. N Engl J Med 353 (25):2643-2653

3. Groop PH, Thomas MC, Moran JL et al (2009) The presence and severity of chronic kidney disease predicts all-cause mortality in type 1 diabetes. Diabetes 58(7):1651-1658. https://doi.org/10. $2337 / d b 08-1543$

4. Janghorbani M, Hu FB, Willett WC et al (2007) Prospective study of type 1 and type 2 diabetes and risk of stroke subtypes: the Nurses' Health Study. Diabetes Care 30(7):1730-1735. https:// doi.org/10.2337/dc06-2363
5. Thorn LM, Shams S, Gordin D et al (2019) Clinical and MRI features of cerebral small-vessel disease in type 1 diabetes. Diabetes Care 42(2):327-330. https://doi.org/10.2337/dc18-1302

6. Nunley KA, Ryan CM, Orchard TJ et al (2015) White matter hyperintensities in middle-aged adults with childhood-onset type 1 diabetes. Neurology 84(20):2062-2069

7. Meissner A (2016) Hypertension and the brain: a risk factor for more than heart disease. Cerebrovasc Dis 42(3-4):255-262. https://doi.org/10.1159/000446082

8. Eriksson MI, Gordin D, Shams S et al (2020) Nocturnal blood pressure is associated with cerebral small-vessel disease in type 1 diabetes. Diabetes care 43(8):e96-e98. https://doi.org/10.2337/ dc20-0473

9. Wardlaw JM, Smith EE, Biessels GJ et al (2013) Neuroimaging standards for research into small vessel disease and its contribution to ageing and neurodegeneration. Lancet Neurol 12(8):822838. https://doi.org/10.1016/s1474-4422(13)70124-8

10. Nansseu JR, Fokom-Domgue J, Noubiap JJ et al (2015) Fructosamine measurement for diabetes mellitus diagnosis and monitoring: a systematic review and meta-analysis protocol. BMJ Open 5(5):e007689. https://doi.org/10.1136/bmjopen-2015-007689

11. Roohk HV, Zaida AR (2008) A review of glycated albumin as an intermediate glycation index for controlling diabetes. J Diabetes Sci Technol 2:1114-1121

12. Wright LA, Hirsch IB (2017) Metrics beyond hemoglobin A1C in diabetes management: time in range, hypoglycemia, and other parameters. Diabetes Technol Ther 19(S2):S16-S26. https://doi. org/10.1089/dia.2017.0029

13. Waden J, Forsblom C, Thorn LM et al (2009) A1C variability predicts incident cardiovascular events, microalbuminuria, and overt diabetic nephropathy in patients with type 1 diabetes. Diabetes 58(11):2649-2655. https://doi.org/10.2337/db09-0693

14. Rhode H, Muckova P, Buchler R et al (2019) A next generation setup for pre-fractionation of non-denatured proteins reveals diverse albumin proteoforms each carrying several post-translational modifications. Sci Rep 9(1):11733. https://doi.org/10.1038/ s41598-019-48278-y

15. Baker JR, Metcalf PA, Johnson RN, Newman D, Rietz P (1985) Use of protein-based standards in automated colorimetric determinations of fructosamine in serum. Clin Chem 31(9):1550-1554

16. Kilpatrick ES, Rigby AS, Atkin SL (2006) The effect of glucose variability on the risk of microvascular complications in type 1 diabetes. Diabetes Care 29(7):1486-1490. https://doi.org/10.2337/ dc06-0293

17. Shen Y, Zhou J, Shi L et al (2021) Association between visit-tovisit $\mathrm{HbA} 1 \mathrm{c}$ variability and the risk of cardiovascular disease in patients with type 2 diabetes. Diabetes Obes Metab 23(1):125135. https://doi.org/10.1111/dom.14201

18. Sheng C-S, Tian J, Miao Y et al (2020) Prognostic significance of long-term $\mathrm{HbA1c}$ variability for all-cause mortality in the ACCORD trial. Diabetes Care 43(6):1185-1190. https://doi.org/ $10.2337 / \mathrm{dc} 19-2589$

19. Weinger K, Jacobson AM, Musen G et al (2008) The effects of type 1 diabetes on cerebral white matter. Diabetologia 51(3):417425. https://doi.org/10.1007/s00125-007-0904-9

20. Akoudad S, Portegies ML, Koudstaal PJ et al (2015) Cerebral microbleeds are associated with an increased risk of stroke: the rotterdam study. Circulation 132(6):509-516. https://doi.org/10. 1161/CIRCULATIONAHA.115.016261

21. Charidimou A, Shams S, Romero JR et al (2018) Clinical significance of cerebral microbleeds on MRI: a comprehensive metaanalysis of risk of intracerebral hemorrhage, ischemic stroke, mortality, and dementia in cohort studies (v1). Int J Stroke 13(5):454-468. https://doi.org/10.1177/1747493017751931 
22. Schofield J, Ho J, Soran H (2019) Cardiovascular risk in type 1 diabetes mellitus. Diabetes Ther 10(3):773-789. https://doi.org/ 10.1007/s13300-019-0612-8

23. Hägg S, Thorn LM, Forsblom CM et al (2014) Different risk factor profiles for ischemic and hemorrhagic stroke in type 1 diabetes mellitus. Stroke 45(9):2558-2562. https://doi.org/10.1161/ STROKEAHA.114.005724

24. Ceriello A, Monnier L, Owens D (2019) Glycaemic variability in diabetes: clinical and therapeutic implications. Lancet Diabetes Endocrinol 7(3):221-230. https://doi.org/10.1016/s2213-8587(18) 30136-0

25. Virk SA, Donaghue KC, Cho YH et al (2016) Association between $\mathrm{HbA} 1 \mathrm{c}$ variability and risk of microvascular complications in adolescents with type 1 diabetes. J Clin Endocrinol Metab 101(9):3257-3263. https://doi.org/10.1210/jc.2015-3604

26. Kilpatrick ES, Rigby AS, Atkin SL (2008) A1C variability and the risk of microvascular complications in type 1 diabetes: data from the diabetes control and complications trial. Diabetes Care 31(11):2198-2202. https://doi.org/10.2337/dc08-0864

27. Kilpatrick ES, Rigby AS, Atkin SL (2009) Effect of glucose variability on the long-term risk of microvascular complications in type 1 diabetes. Diabetes Care 32(10):1901-1903. https://doi.org/ 10.2337/dc09-0109

28. Chmielewska B, Hasiec T, Belniak-Legieć E (1996) Value of glucose, glycosylated hemoglobin and fructosamine in blood of patients with ischemic cerebral infarction without diabetes during the early stage of the disease. Ann Univ Mariae Curie Sklodowska Med 51:61-68

29. Chmielewska B, Hasiec T, Belniak-Legieć E (1995) The concentration of glucose, glycosylated hemoglobin and fructosamine in blood of patients with cerebral hemorrhage in the acute stage of the disease. Ann Univ Mariae Curie Sklodowska Med 50:123-130

30. Lee SH, Jang MU, Kim Y et al (2020) Effect of prestroke glycemic variability estimated glycated albumin on stroke severity and infarct volume in diabetic patients presenting with acute ischemic stroke. Front Endocrinol (Lausanne) 11:230. https://doi.org/10. 3389/fendo.2020.00230

31. Lee SH, Kim Y, Park SY, Kim C, Kim YJ, Sohn JH (2021) Prestroke glycemic variability estimated by glycated albumin is associated with early neurological deterioration and poor functional outcome in prediabetic patients with acute ischemic stroke. Cerebrovasc Dis 50(1):26-33. https://doi.org/10.1159/000511938
32. Rabbani N, Thornalley PJ (2021) Protein glycation - biomarkers of metabolic dysfunction and early-stage decline in health in the era of precision medicine. Redox Biol 42:101920. https://doi.org/ 10.1016/j.redox.2021.101920

33. Hainsworth DP, Bebu I, Aiello LP et al (2019) Risk factors for retinopathy in type 1 diabetes: the DCCT/EDIC study. Diabetes Care 42(5):875-882. https://doi.org/10.2337/dc18-2308

34. Woerdeman J, van Duinkerken E, Wattjes MP et al (2014) Proliferative retinopathy in type 1 diabetes is associated with cerebral microbleeds, which is part of generalized microangiopathy. Diabetes Care 37(4):1165-1168. https://doi.org/10.2337/dc13-1586

35. Sanahuja J, Alonso N, Diez J et al (2016) Increased burden of cerebral small vessel disease in patients with type 2 diabetes and retinopathy. Diabetes Care 39(9):1614-1620. https://doi.org/10. 2337/dc15-2671

36. Eriksson MI, Summanen P, Gordin D et al (2021) Cerebral smallvessel disease is associated with the severity of diabetic retinopathy in type 1 diabetes. BMJ Open Diabetes Res Care. https://doi. org/10.1136/bmjdrc-2021-002274

37. McCall AL (2004) Cerebral glucose metabolism in diabetes mellitus. Eur J Pharmacol 490(1-3):147-158. https://doi.org/10.1016/j. ejphar.2004.02.052

38. Patching SG (2017) Glucose transporters at the blood-brain barrier: function, regulation and gateways for drug delivery. Mol Neurobiol 54(2):1046-1077. https://doi.org/10.1007/ s12035-015-9672-6

39. Prasad S, Sajja RK, Naik P, Cucullo L (2014) Diabetes mellitus and blood-brain barrier dysfunction: an overview. J Pharmacovigil 2(2):125. https://doi.org/10.4172/2329-6887.1000125

40. Freeze WM, Jacobs HIL, Schreuder F et al (2018) Blood-brain barrier dysfunction in small vessel disease related intracerebral hemorrhage. Front Neurol 9:926. https://doi.org/10.3389/fneur. 2018.00926

Publisher's Note Springer Nature remains neutral with regard to jurisdictional claims in published maps and institutional affiliations.

\section{Authors and Affiliations}

\section{Jussi Inkeri ${ }^{1,2} \cdot$ Krishna Adeshara $^{2,3,4}$. Valma Harjutsalo ${ }^{2,3,4} \cdot$ Carol Forsblom $^{2,3,4} \cdot$ Ron Liebkind $^{5}$. Turgut Tatlisumak ${ }^{5,6,7} \cdot$ Lena M. Thorn ${ }^{2,4,8} \cdot$ Per-Henrik Groop ${ }^{2,3,4,9}$ (D) Sara Shams ${ }^{10,11,12} \cdot$ Juha Martola $^{1,11}$. Jukka Putaala ${ }^{5}$ Daniel Gordin ${ }^{3,13,14}$ - on behalf of the FinnDiane Study Group}

$1 \quad$ HUS Medical Imaging Center, Radiology, University of Helsinki and Helsinki University Hospital, Helsinki, Finland

2 Folkhälsan Institute of Genetics, Folkhälsan Research Center, Helsinki, Finland

3 Department of Nephrology, University of Helsinki and Helsinki University Hospital, Helsinki, Finland

4 Research Program for Clinical and Molecular Metabolism, University of Helsinki, Helsinki, Finland

5 Neurology, University of Helsinki and Helsinki University Hospital, Helsinki, Finland
6 Department of Clinical Neuroscience/Neurology, Institute of Neuroscience and Physiology, Sahlgrenska Academy, University of Gothenburg, Gothenburg, Sweden

7 Department of Neurology, Sahlgrenska University Hospital, Gothenburg, Sweden

8 Department of General Practice and Primary Health Care, University of Helsinki and Helsinki University Hospital, Helsinki, Finland

9 Department of Diabetes, Central Clinical School, Monash University, Melbourne, Australia

10 Department of Radiology, Karolinska University Hospital, Stockholm, Sweden 
11 Department of Clinical Neuroscience, Karolinska Institute, Stockholm, Sweden

12 Department of Radiology, Stanford University, Stanford, CA, USA
13 Minerva Foundation Institute for Medical Research, Helsinki, Finland

14 Joslin Diabetes Center, Harvard Medical School, Boston, MA, USA 